\title{
Posterior decompression and stabilization for metastatic compression of the thoracic spinal cord: is this procedure still state of the art?
}

\author{
R Abel, M Keil, E Schläger and M Akbar \\ Orthopädische Universitätsklinik Heidelberg, Germany
}

\begin{abstract}
Study Design: Retrospective study utilizing the standard patient data documentation of a spinal cord injury $(\mathrm{SCl})$ unit.

Objective: To examine the efficacy and outcome of posterior decompression and stabilization for metastatic cord compression.

Setting: Orthopedic university hospital with large $\mathrm{SCl}$ unit.

Methods: The 34 consecutive patients who had presented with symptoms of spinal cord compression due to metastatic disease and progressive neurologic deficit were treated using a uniform surgical approach (posterior decompression and stabilization). After surgery, all treatment options available in a full-featured SCI unit were applied as necessary and suitable. Outcome was rated concerning neurologic function (American Spinal Injury Association, ASIA), functional status (Functional Independence Measure) and pain. The results were compared to the published results, focusing on publications describing results of anterior surgical approaches to the spine.

Results: Evaluation of the results of the ASIA exams showed that progression of the neurologic deficit could be stopped in the majority of cases - however recovery of neurologic function was rare. The functional status could be improved markedly and good pain reduction was achieved.

Conclusion: Immediate surgery can be recommended if the general condition of the patient warrants surgical intervention. Using accepted standards of documentation for $\mathrm{SCl}$, a clear perspective of the results that can be expected is provided. Comparing the results of this study with the current literature there is no evidence that anterior approaches are superior.
\end{abstract}

Spinal Cord (2008) 46, 595-602; doi:10.1038/sc.2008.11; published online 4 March 2008

Keywords: spinal cord injury; spinal metastasis; surgery; decompression; stabilization; survival

\section{Introduction}

Metastatic compression of the spinal cord is a dreaded complication of tumors. Unfortunately, the spine is the most common site of bone metastasis (Wise et al., ${ }^{1}$ 39\%). The functional and vital status of the patients varies considerably. Most of the time sophisticated chemotherapy and radiation schemes have already been used to treat the underlying disease before the onset of neurologic dysfunction.

Surgical techniques employing anterior, posterior or combined approaches are available for decompression and stabilization. ${ }^{2}$ Multiple studies have been published reporting the results of such procedures (Table 2). Most of them are based on patient populations that are not uniform regarding the level of the lesion (thoracic or lumbar) or neurologic deficit. They focus on survival whereas

Correspondence: Priv Doz Dr R Abel, Klinik für Querschnittgelähmte, SCI Unit, Hohe Warte 8; Bayreuth D-94554, Germany.

E-mail: abel rainer@hotmail.com

Received 2 March 2007; revised 6 December 2007; accepted 13 January 2008; published online 4 March 2008 the description of the neurologic deficit is generally limited to Frankel grading or function (for example, ambulatory vs nonambulatory). Detailed data meeting the internationally accepted standards of the American Spinal Injury Association (ASIA) classification ${ }^{3}$ are lacking. Furthermore, many studies include data on patients treated with different procedures.

In the presence of symptomatic compression of the spinal cord by metastatic lesions, the tumor often has progressed beyond a point where surgical intervention can help to eradicate it. The rationale for this intervention is to relieve pain and to stop or reverse the progression of the neurologic deficit. ${ }^{1}$ It has been hypothesized that anterior approaches are more effective because the metastatic mass often arises from the vertebral body. ${ }^{4,5}$

In the present study we attempt to provide a clear perspective of the results that can be expected of posterior decompression and screw-rod fixation in the thoracic spine when significant metastatic compression of the spinal cord causes progressive neurologic dysfunction. 


\section{Patients and methods}

The computerized database of our spinal cord injury (SCI) unit was used to identify 45 consecutive patients who had presented with symptoms of spinal cord compression due to metastatic disease and were admitted between January 1997 and December 2000.

Patients were included when the major part of the neurologic deficit had developed within 7 days prior to admission. The neurologic deficit had to be progressive at the time of presentation at the hospital. The level of lesion had to be identified between $\mathrm{C} 8$ and the medullary conus (L1). Thirty-four patients met these criteria and were then entered into this study. The mean age at the time of the admission was 60 years, ranging from 27 to 85 years.

\section{Treatment}

The treatment followed a standardized protocol. Surgery was considered when the neurologic examination matched the findings of the magnetic resonance imaging regarding the level of the presumed compression of the spinal cord. Patients had to be in acceptable clinical condition for surgery. The goal of surgery was decompression and stabilization. Decompression of the spinal cord was carried out by posterior and posterolateral removal of compressive intraspinal tumor tissue. The spine was stabilized employing a screw-rod construct with four pedicle screws above and below the lesion (Figures $1 \mathrm{a}$ and $\mathrm{b}$ ). For lesions of the cervicothoracic junction Luque wires were employed for the cervical part of the spine.
The instrumentation was controlled postoperatively by plain X-ray. An additional radiographic control was performed before discharge when the patient was on our ward for more than 3 weeks after surgery or when the patient developed or had continuing local pain.

All subjects were scheduled for posterior decompression and stabilization within $24 \mathrm{~h}$ of admission. A total of 34 individuals met the inclusion criteria, 6 of them women, 28 men.

After surgery, all treatment options available in a fullfeatured SCI unit, including physical therapy for mobilization, occupational therapy to adjust the necessary aids and psychological counseling were offered. The treatment was adjusted to the clinical situation as necessary; oncologic treatment was either continued or started after surgery with irradiation or chemotherapy as indicated. Corticoids were not part of the treatment protocol.

Special emphasis was directed toward maintenance or achievement of urinary and fecal continence.

\section{Assessment of clinical and neurologic status}

The tumor type was noted as were all complications that occurred while the patient was on the ward.

The routine documentation at admission included a detailed description of the neurologic deficit, the functional status and the medication, especially the amount and type of pain medication. To assess ambulation status, all patients able to walk at least $10 \mathrm{~m}$, regardless of the type of aid necessary, were categorized as ambulatory. All patients with
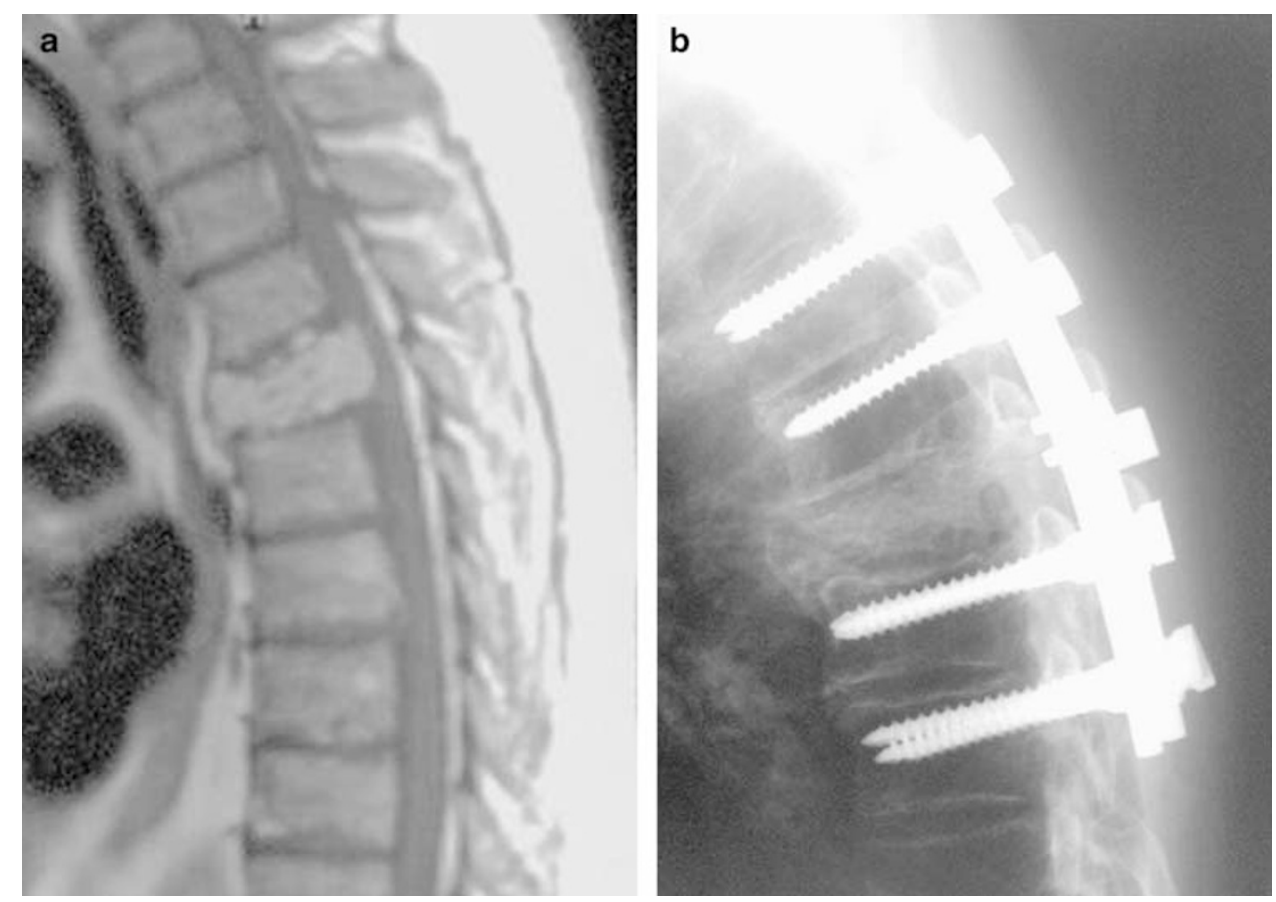

Figure $1(\mathbf{a}, \mathbf{b})$ This is a typical example of spinal cord compression by metastatic disease of the spine. This patient's tumor was diagnosed as adenocarcinoma of the lung. He presented with complete loss of motor function (motor ASIA 50), some sensory function left (light touch ASIA 60 ) and severe pain. Due to pain he could not sit. He was operated and regained some motor function (motor ASIA 62) and, more importantly, showed improved sensibility (light touch ASIA 85). This included the ability to feel coming bowel movements, a function that proved to be of great benefit. He was mobilized with minimal pain into a wheelchair; he did not recover any walking ability. The patient survived 11 months after surgery. ASIA, American Spinal Injury Association. 
less walking ability were categorized as nonambulatory. At discharge the assessment was repeated and the findings added to the documentation.

The ASIA score, developed by the American Spinal Injury Association, was employed to document the neurologic deficit. ${ }^{3}$ This includes tests of key muscles and of sensibility to touch and pinprick. The functional status was rated using the complete Functional Independence Measure (FIM), a test developed by Ditunno et al. ${ }^{6}$ covering all activities of daily living from bladder control to mobility. The score only calculates what the patient actually does, not their mere potential to do something. Accordingly, a patient with the neurologic competence to dress but who was in disabling pain was categorized into 'requiring assistance to dress'.

To ensure standardization, the documentation was performed only by persons who had received adequate training and experience to apply the measurement scores.

\section{Pain}

To address the results of the treatment concerning pain, patients were grouped into one of the following four categories:

Group I; no pain medication necessary at admission and discharge.

Group II; pain medication necessary at admission and discharge, but reduced dose or change to less potent medication possible (for example, morphine to nonsteroidal anti-inflammatory drugs).

Group III; need for pain medication unchanged.

Group IV; increased need for pain medication.

\section{Discharge}

Furthermore, we recorded whether the patient was discharged home or to a nursing home or transferred to another hospital.

When very early discharge was required, for example, transfers for radiation therapy, the clinical scores were reevaluated using data from the outpatient records.

\section{Results}

All 34 patients spent 45 days (mean, range 5-120 days) on the ward. Three patients died on the ward 8, 32 and 38 days after admission due to complications associated with the underlying tumor, such as pulmonary effusion. One of these patients explicitly declined further treatment. These three patients were excluded from analysis of outcome concerning pain, neurologic deficit and function.

As stated, for all patients the initial treatment plan included decompression and posterior stabilization. In two cases it became obvious during surgery that the metastatic destruction made it impossible to anchor any screws. Surgery had to be concluded after decompression.

A listing of the tumor types noted and their frequency is given in Table 1.

Six patients developed postsurgical complications. There were two cases of deep vein thrombosis and one lung embolism. They occurred despite a strict protocol of weight-adjusted low-molecular-weight heparin administration. One patient suffered upper gastrointestinal bleeding. There was one case of pneumonia associated with lung atelectasis induced by metastasis in the lung. One deep wound infection necessitated revision surgery.

A review of the radiographic controls did not show gross misplacement of screws or instrumentation failures.

\section{Neurologic status}

According to the inclusion criteria, all patients accepted into this study had developed most of the neurologic deficit within the last 7 days prior to admission and still showed progressive loss of function. Thirty-one had neurogenic impairment of bladder control; three could void normally.

The neurologic status deteriorated in four cases $(13 \%)$. Twice, severe additional neurologic defects were evident immediately after surgery. The other two patients experienced gradual progression of the deficit despite the surgical procedure. In 18 cases the neurologic situation remained unchanged (48\%); 12 patients experienced improvements (39\%).

The average ASIA score for light touch (maximum value 112) at admission was 73.32 (standard deviation 20.67) and improved to 82.82 (standard deviation 21.30) at discharge $(P=0.07 ; t$-test). The average ASIA score for sensation of pinprick at admission was 71.93 (standard deviation 23.11) and 79.90 (standard deviation 24.32) at discharge. This difference was not significant either ( $t$-test). Figures $2 \mathrm{a}$ and $\mathrm{b}$ demonstrate the results concerning the sensory deficits.

There was no significant difference between the mean ASIA motor score (maximum 100) at admission and discharge (72.1 vs $73.5 ; P>0.7$; $t$-test). Figure 3 gives the details of motor function development for 31 patients; data for the 3 patients who died on the ward were omitted.

At admission, 3 patients were able to walk; 31 were not ambulatory. Four patients regained ambulation; in two patients who could walk this function was preserved. One patient lost his ability to walk after surgery due to intraspinal hemorrhage.

It has to be noted that several patients did not regain the ability to walk despite good motor function. Due to tumorassociated maladies (for example, kachexia) these patients were too weak to ambulate.

\section{Functional status}

Twenty-six patients were able to participate in the rehabilitation therapy offered by the SCI unit as described above.

Table 1 Tumor type and frequency of observation

\begin{tabular}{lc} 
Tumor type & Number of patients \\
\hline Prostate gland carcinoma & 7 \\
Renal carcinoma & 4 \\
Lung carcinoma & 6 \\
Plasmocytoma & 5 \\
Breast carcinoma & 3 \\
Other & 8 \\
Unknown & 1
\end{tabular}



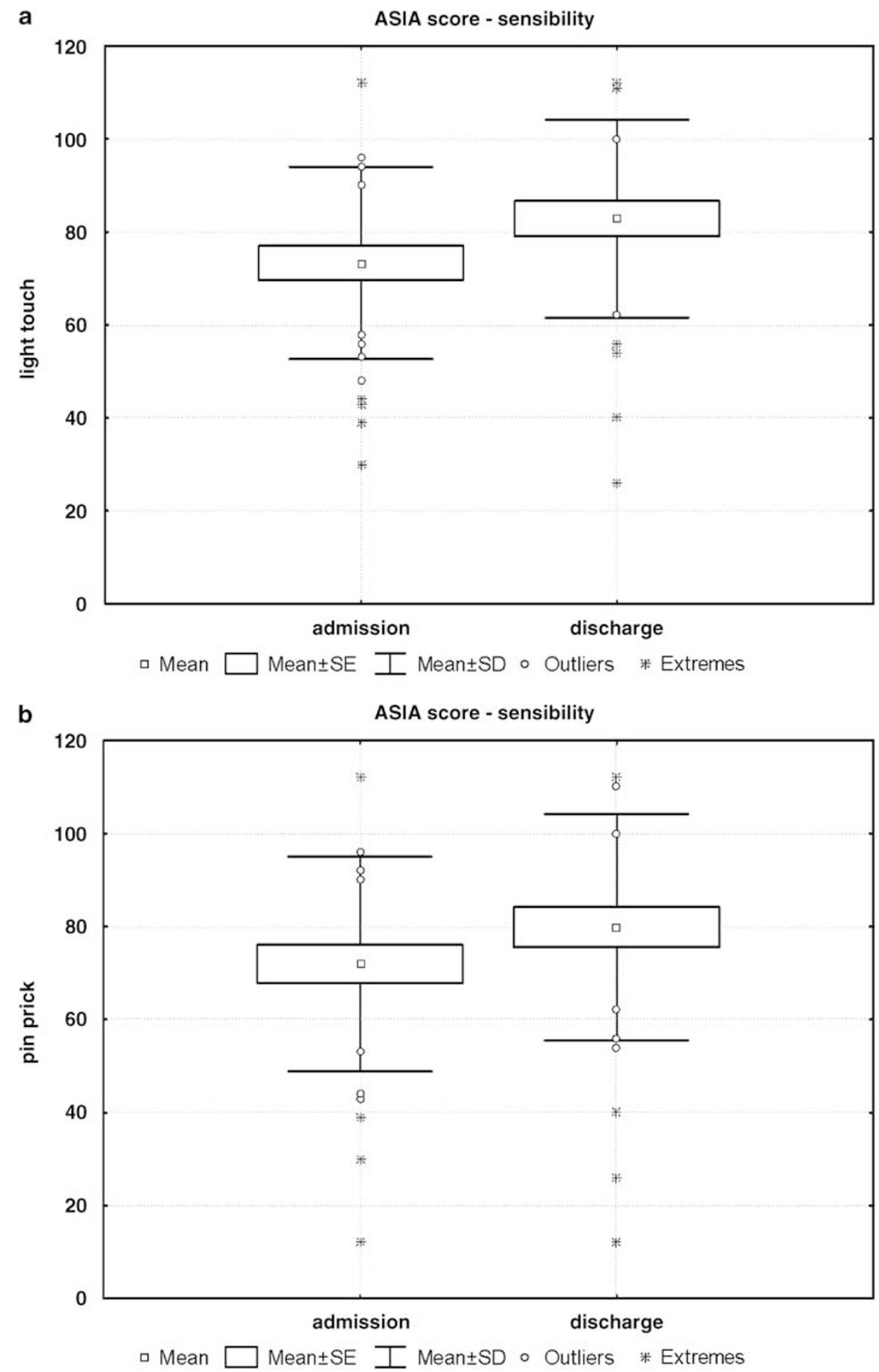

Figure 2 (a, b) Results of the American Spinal Injury Association (ASIA) scores at admission and discharge concerning light touch and pinprick. There is no significant difference.

However, five patients were discharged after surgery without any substantial rehabilitation effort being possible. Four were transferred for immediate radiation therapy, and one patient chose to decline further treatment and was discharged home. These subjects were inpatients for 8.8 days (range 5-13 days). The ASIA and functional scores were reevaluated when these patients were seen in the outpatient clinic 41-63 days after surgery. No substantial change was noted compared to the discharge status.

The functional status results as measured by the FIM were markedly improve-d (64.6 vs 81.9 ) when comparing the initial status to the discharge status (Figure 4). This result is highly significant ( $t$-test; $P<0.01$ ). 

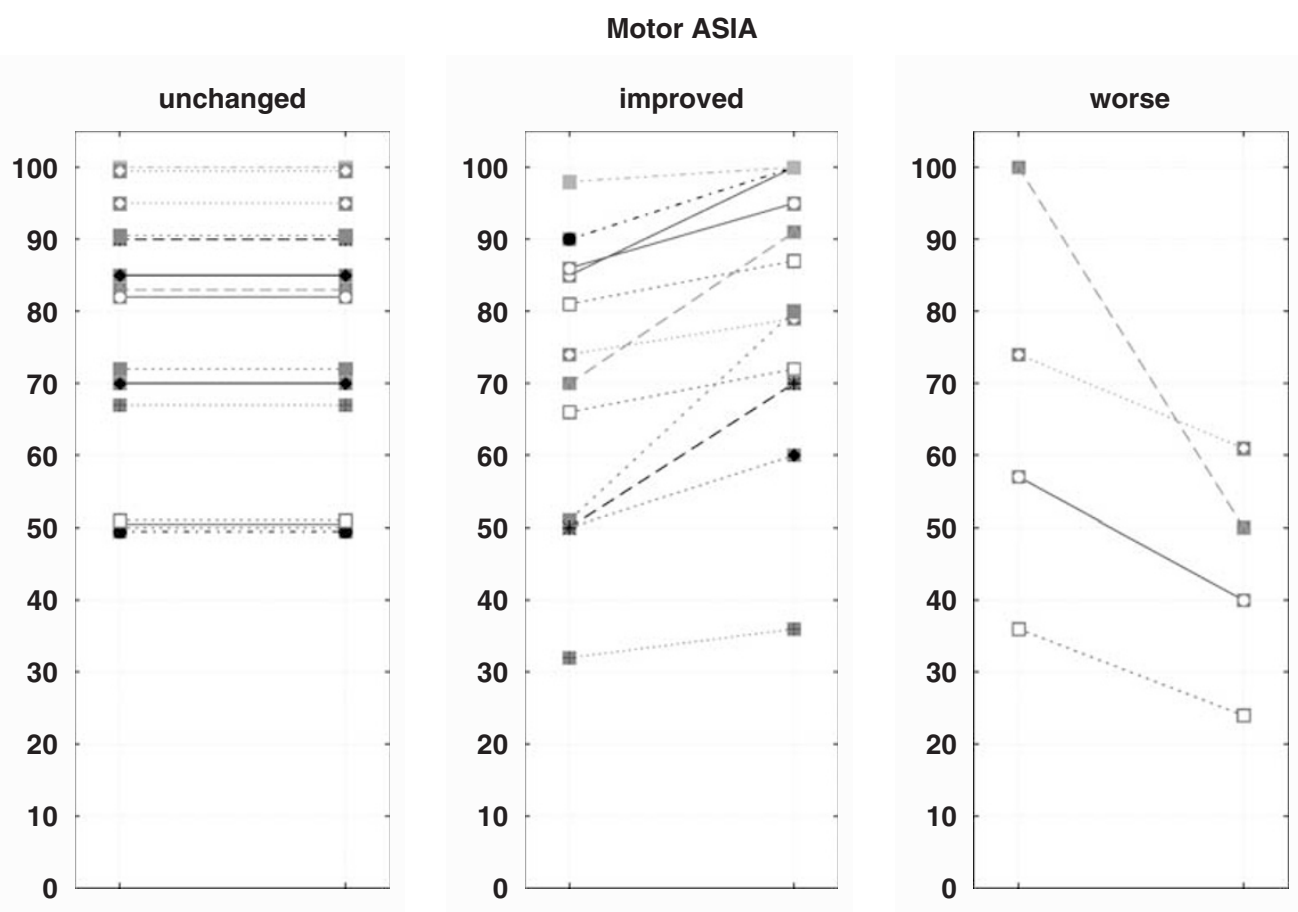

Figure 3 Results of the American Spinal Injury Association (ASIA) scores at admission and discharge concerning motor function (maximum 100). The results are given for each individual at admission and discharge.

In total, 17 of our patients could be discharged to their home, 12 were transferred to other hospitals and 2 had to be placed in a nursing home. Of those transferred, 10 ultimately were also discharged home. Information on the final discharge of the two remaining patients was not available.

\section{Pain}

Two patients did not complain of pain (Group I). Twenty patients improved to a point where the dose and type of medication necessary could be reduced or changed to less potent substances (Group II). For six patients there was no change in the need for medication (Group III), and three patients required more potent pain medication upon discharge than at admission (Group IV).

All three patients who died on the ward received adequate dosages of pain and sedating medication.

\section{Survival}

Survival was calculated according to data retrieved from public administration databases in March 2003. At this time six subjects were alive. Survival analysis employing the Kaplan-Meier product limit method was used (Figure 5). The median survival was 15.1 month (25th percentile, 4.5 months; 75th percentile, 27.4 months).

\section{Discussion}

Unfortunately, metastasis to the spine with subsequent damage to the spinal cord is a rather frequent problem for patients with malignant tumors. Studies estimate that
3-7.4\% of patients with lung, breast and prostate cancer will present with metastatic cord compression. ${ }^{2}$

Metastatic spread to the spine always represents progression of the underlying disease, limiting chances for survival. Surgical options have to be chosen that take factors like other metastatic lesions and tumor type into account. Scores have been proposed ${ }^{7,8}$ to aid in decision-making.

Besides being important for the quality of life, functional capabilities correlate with survival. ${ }^{7,9,10}$ Since the functional status greatly depends on the neurologic deficit, it is very important to determine the efficacy of a procedure in terms of neurologic recovery. Metastatic cord compression supposedly causes progressive neurologic deficit by not only impairing the blood flow to and from the cord but also as a result of direct mechanical pressure. There is a great difference in the susceptibility toward this kind of damage between fibers of the cauda equina and the spinal cord itself. This implies that care has to be taken only to compare and summarize results when the level of lesion is consistent.

Over the past 20 years numerous studies on surgery for metastatic lesions of the spine have been published. The focus is shifting to anterior procedures; some authors advocate anterior approaches, reasoning that the decompression may be more effective since the tumor is usually located in the anterior parts of the spine. ${ }^{4,5,11}$

Table 2 lists the studies that describe patients with metastatic spinal cord compression, include more than 10 patients and provide sufficient information to allow comparison concerning the neurologic outcomes. ${ }^{1,411-22}$

As a description of the neurologic status before and after surgery, the Frankel score or a categorization by 


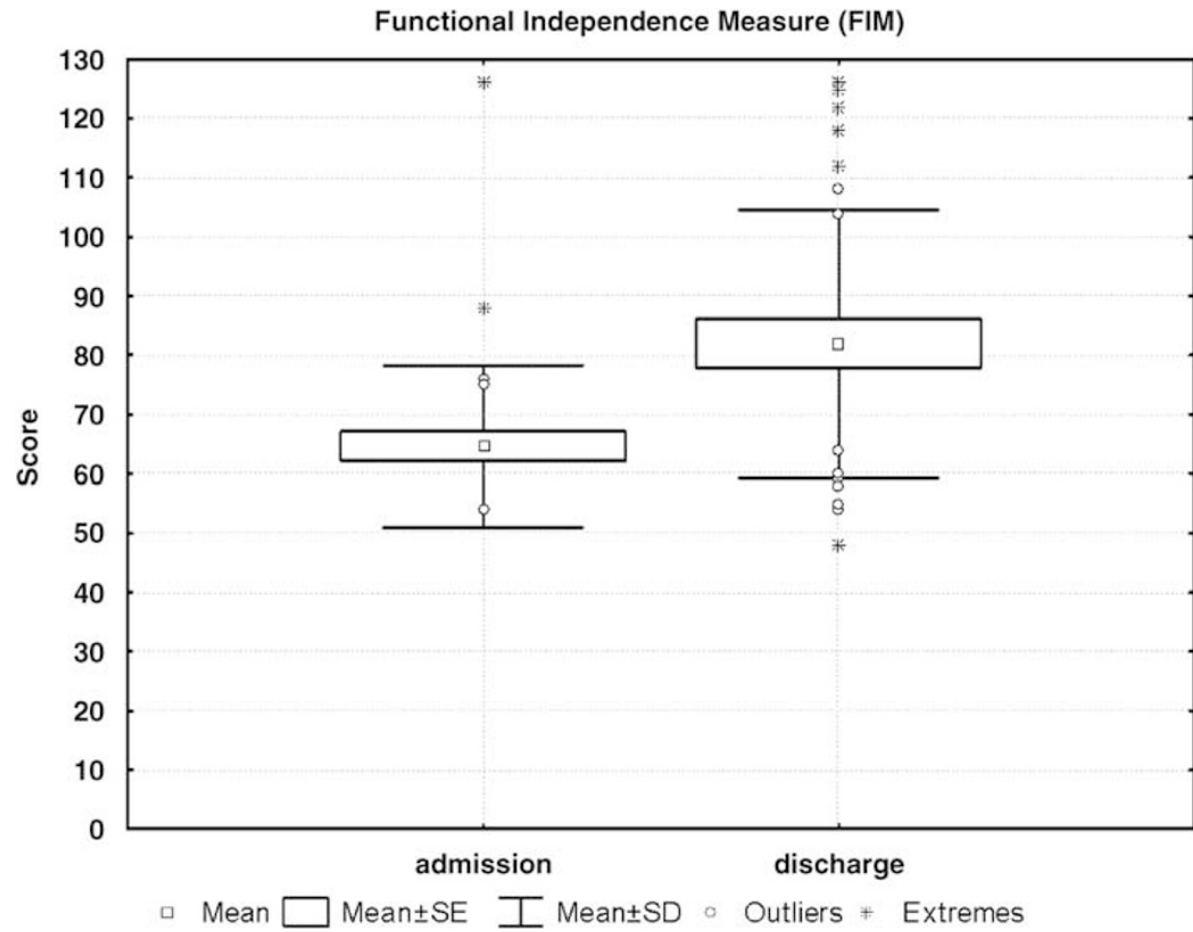

Figure 4 Functional outcome as measured by the Functional Independence Measure (FIM) score.

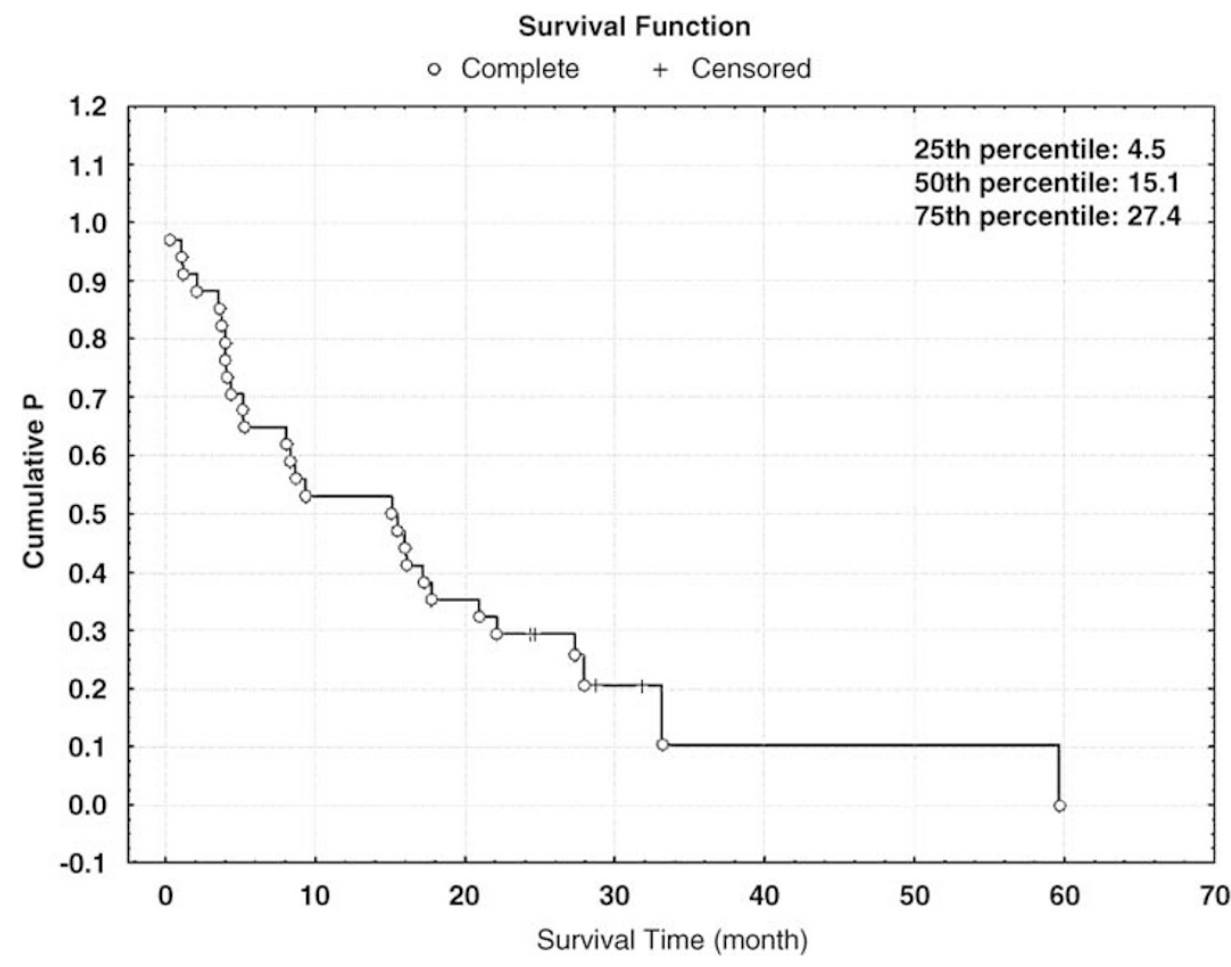

Figure 5 Survival analysis. The graph demonstrates the results of the survival analysis for 34 patients presenting to our institution between January 1997 and December 2000 who met the inclusion criteria. Six patients were still alive in March 2003 (identified as 'censored' in the graph).

functional capacity is usually given. Both approaches pose difficulties. The Frankel grading is not very detailed; therefore, it is difficult to assess smaller changes in neurologic function. The American Spinal Injury Association has established the ASIA score as a better tool to rate the neurologic status. ${ }^{3}$

A categorization by function alone is also problematic, for example, because the inability to walk may be due to pain 
Table 2 Studies including more than 10 patients with neurologic deficit identified by a Medline query with the keywords 'metastasis', 'spine' and 'surgery/decompression'

\begin{tabular}{|c|c|c|c|c|c|c|c|c|c|c|c|}
\hline Author & Procedure & $\mathrm{n}$ & $\begin{array}{c}\text { n (neurologic } \\
\text { deficit) }\end{array}$ & $\begin{array}{l}\text { Neurologic } \\
\text { grading }\end{array}$ & Thoracic lesion & Result: Worse & Result: Same & Result: Better & $\begin{array}{l}\text { Pain } \\
\text { grading }\end{array}$ & Pain relieve & Survival \\
\hline Jansson et al. ${ }^{22}$ & Mixed & $\begin{array}{c}282 \text { (67 } \\
\text { previously } \\
\text { published by } \\
\text { Bauer et al.?) }\end{array}$ & 282 & Frankel & 254 & 12 & 63 & 179 & $?$ & $\begin{array}{l}\text { No } \\
\text { comment }\end{array}$ & $\begin{array}{l}1 \text { year survival: } \\
28 \%\end{array}$ \\
\hline Yen et al. ${ }^{12}$ & Anterior & 27 & 25 & Frankel & $?$ & $0 \%$ & $78 \%$ & $22 \%$ & $?$ & $\begin{array}{l}\text { No } \\
\text { comment }\end{array}$ & $\begin{array}{l}261 \text { days } \\
\text { (mean) }\end{array}$ \\
\hline Chen et al. ${ }^{4}$ & Anterior & 60 & 46 & Frankel & $40(60)$ & 0 & $28 \%$ & 72 & Activity & Yes & $\begin{array}{l}\text { 6-12 months } \\
\text { (median) }\end{array}$ \\
\hline Gokaslan et al. ${ }^{11}$ & Anterior & 72 & 46 & Frankel & $72(72)$ & 1 & 10 & 35 & Score & Yes & $\begin{array}{l}1 \text { year survival: } \\
61 \%\end{array}$ \\
\hline Akeyson et al. ${ }^{20}$ & $\begin{array}{l}\text { Posterolateral } \\
\text { resection }\end{array}$ & 25 & 15 & Function & $13(15)$ & 0 & 7 & 8 & $?$ & Yes & $\begin{array}{l}29.5 \text { weeks } \\
\text { (mean) }\end{array}$ \\
\hline Rompe et al. ${ }^{21}$ & Posterior & 106 & 56 & Frankel & $76(106)$ & 2 & 19 & 35 & Score & Yes & $\begin{array}{l}19.2 \text { months } \\
\text { (mean) }\end{array}$ \\
\hline Bauer et al..$^{19}$ & Posterior & 67 & 56 & Frankel & $41(26)$ & 2 & 10 & 44 & $?$ & $\begin{array}{l}\text { No } \\
\text { comment }\end{array}$ & $\begin{array}{l}1 \text { year survival: } \\
22 \%\end{array}$ \\
\hline Jonsson et al. ${ }^{18}$ & Posterior & 51 & 46 & Function & $37(51)$ & $0 \%$ & $50 \%$ & $50 \%$ & $?$ & Yes & $\begin{array}{l}8 \text { months } \\
\text { (median) }\end{array}$ \\
\hline Tomita et al. ${ }^{14}$ & Mixed & 61 & 34 & Frankel & $?$ & $0 \%$ & $26 \%$ & $74 \%$ & Score & $\begin{array}{l}\text { Yes } \\
\text { 'majority' }\end{array}$ & $\begin{array}{l}10.1-38.2 \\
\text { months (several } \\
\text { means given for } \\
\text { subgroups) }\end{array}$ \\
\hline Hussein et al. ${ }^{13}$ & Mixed & 21 & 21 & $?$ & $?$ & $0 \%$ & $0 \%$ & $100 \%$ & $?$ & $100 \%$ & $?$ \\
\hline Wise et al. ${ }^{1}$ & Mixed & 80 & 30 & Frankel & $?$ & 2 & 9 & 19 & $?$ & $\begin{array}{l}\text { No } \\
\text { comment }\end{array}$ & $\begin{array}{l}15.9 \text { months } \\
\text { (mean) }\end{array}$ \\
\hline Onimus et al. ${ }^{15}$ & Mixed & 100 & 38 & Frankel & $?$ & 8 & 30 & Score & Yes & 10 & $?$ \\
\hline Timlin $^{16}$ & Mixed & 28 & 28 & $?$ & $?$ & 9 & 17 & $?$ & Yes & $\begin{array}{l}6.4 \text { months } \\
\text { (mean) }\end{array}$ & $?$ \\
\hline Manabe $^{17}$ & Mixed & 28 & 17 & Frankel & $11(17)$ & $?$ & $?$ & $75 \%$ & $?$ & Yes & $?$ \\
\hline
\end{tabular}

Question marks are used if the information could not be extracted from the paper. 
rather than neurologic deficit. The differences in the presentation of the initial clinical status may explain some of the wide deviation of results reported.

By employing posterior decompression and stabilization with a screw-rod construct to tumors of the thoracic spine with paraplegia we succeeded in stopping the progression of the neurologic deficit. However, the changes documented by the ASIA score were limited. Patients reached only values within a range of 20 to the score at admission, and no patient recovered fully. Even patients regaining ambulatory status had some remaining deficit. By no means is surgical decompression without risk. In two cases surgery resulted in functionally relevant deterioration.

Our results support the notion that surgery should be performed on an emergency basis. Every bit of spinal cord function lost while a patient is waiting for a decision, the right surgeon and so on will add to the disability. This does not preclude surgery for patients with a long history of paraplegia. It is very likely that they will benefit, for example, from pain reduction. ${ }^{1}$

There is, however, marked improvement in the functional capabilities of the patients as expressed by the FIM score. This is likely largely due to the pain reduction and, to some degree, is the result of rehabilitation. This result is also reflected in the fact that almost all of our patients could finally be discharged home.

Our results fall into the range of results reported by Yen et al., ${ }^{12}$ who employed an anterior approach for a comparable group of patients. It is worse than the results reported by Goskalan et al. ${ }^{11}$ Of 46 patients with neurologic dysfunction in this series, 33 were ambulatory at admission while our series included only 3 patients with the capability of walking preserved at admission. Chen et al. ${ }^{4}$ observed neurologic improvement in $72 \%$ of the patients. Almost $50 \%$ of patients in this series had lesions of the lumbar spine. The neurologic outcome is not categorized by thoracic and lumbar lesions but the authors state that 'neurologic recovery was more dramatic in the lumbar region'. 4

Other authors who have reviewed posterior approaches also report better results. ${ }^{19,21}$ The value of comparing the results is limited, though, because it is not possible to extract the results of those patients in their series who actually had thoracic spinal cord compression with significant neurologic deficit. The remaining reports identified by our literature search (Table 2) not only present heterogeneous patient populations concerning the location of the lesion but also review different surgical strategies. It is not feasible to compare results here.

Despite the fact that the patients included in this series presented with a less favorable functional status at admission, survival (median 15.9 months) was equal or better than reported in other series (Table 2 ).

We conclude that posterior decompression and stabilization for metastatic compression of the thoracic spinal cord is still an excellent way to treat these patients who have a shortened lifespan and limited function. The procedure allows for good pain control enhancing the comfort of the patient. The progression of the neurologic deficit is stopped in most cases; there is no substantial evidence that the more invasive anterior decompression will yield better results.

\section{References}

1 Wise JJ, Fischgrund JS, Herkowitz HN, Montgomery D, Kurz LT. Complication, survival rates, and risk factors of surgery for metastatic disease of the spine. Spine 1999; 24: 1943-1951.

2 Loblaw DA, Laperriere NJ. Emergency treatment of malignant extradural spinal cord compression: an evidence-based guideline. J Clin Oncol 1998; 16: 1613-1624.

3 Maynard Jr FM, Bracken MB, Creasey G, Ditunno Jr JF, Donovan WH, Ducker TB et al. International standards for neurological and functional classification of spinal cord injury. American Spinal Injury Association. Spinal Cord 1997; 35: 266-274.

4 Chen LH, Chen WJ, Niu CC, Shih $\mathrm{CH}$. Anterior reconstructive spinal surgery with Zielke instrumentation for metastatic malignancies of the spine. Arch Orthop Trauma Surg 2000; 120: 27-31.

5 Dominkus M, Krepler P, Schwameis E, Kotz R. Operative therapie von wirbelsaulenmetastasen. Orthopäde 1998; 27: 282-286.

6 Ditunno Jr JF, Young W, Donovan WH, Creasey G. The international standards booklet for neurological and functional classification of spinal cord injury. American Spinal Injury Association. Paraplegia 1994; 32: 70-80.

7 Tokuhashi Y, Matsuzaki H, Toriyama S, Kawano H, Ohsaka S. Scoring system for the preoperative evaluation of metastatic spine tumor prognosis. Spine 1990; 15: 1110-1113.

8 Enkaoua EA, Doursounian L, Chatellier G, Mabesoone F, Aimard T, Saillant G. Vertebral metastases: a critical appreciation of the preoperative prognostic Tokuhashi score in a series of 71 cases. Spine 1997; 22: 2293-2298.

9 Sioutos PJ, Arbit E, Meshulam CF, Galicich JH. Spinal metastases from solid tumors. Analysis of factors affecting survival. Cancer 1995; 76: 1453-1459.

10 Parsch D, Mikut R, Abel R. Postacute management of patients with spinal cord injury due to metastatic tumour disease: survival and efficacy of rehabilitation. Spinal Cord 2003; 41: 205-210.

11 Gokaslan ZL, York JE, Walsh GL, McCutcheon IE, Lang FF, Putnam Jr JB et al. Transthoracic vertebrectomy for metastatic spinal tumors. J Neurosurg 1998; 89: 599-609.

12 Yen D, Kuriachan V, Yach J, Howard A. Long-term outcome of anterior decompression and spinal fixation after placement of the Wellesley Wedge for thoracic and lumbar spinal metastasis. J Neurosurg 2002; 96 (1 Suppl): 6-9.

13 Hussein AA, El Karef E, Hafez M. Reconstructive surgery in spinal tumours. Eur J Surg Oncol 2001; 27: 196-199.

14 Tomita K, Kawahara N, Kobayashi T, Yoshida A, Murakami H, Akamaru T. Surgical strategy for spinal metastases. Spine 2001; 26: 298-306.

15 Onimus M, Papin P, Gangloff S. Results of surgical treatment of spinal thoracic and lumbar metastases. Eur Spine J 1996; 5: 407-411.

16 Timlin M, Thalgott J, Ameriks J, Jordan F, Kabins M, Gardner V et al. Management of metastatic tumors to the spine using simple plate fixation. Am Surg 1995; 61: 704-708.

17 Manabe S, Tateishi A, Abe M, Ohno T. Surgical treatment of metastatic tumors of the spine. Spine 1989; 14: 41-47.

18 Jonsson B, Sjostrom L, Olerud C, Andreasson I, Bring J, Rauschning W. Outcome after limited posterior surgery for thoracic and lumbar spine metastases. Eur Spine J 1996; 5: 36-44.

19 Bauer HC. Posterior decompression and stabilization for spinal metastases: Analysis of sixty-seven consecutive patients. I Bone Joint Surg Am 1997; 79: 514-522.

20 Akeyson EW, McCutcheon IE. Single-stage posterior vertebrectomy and replacement combined with posterior instrumentation for spinal metastasis. J Neurosurg 1996; 85: 211-220.

21 Rompe JD, Hopf CG, Eysel P. Outcome after palliative posterior surgery for metastatic disease of the spine-evaluation of 106 consecutive patients after decompression and stabilisation with the Cotrel-Dubousset instrumentation. Arch Orthop Trauma Surg 1999; 119: 394-400.

22 Jansson KA, Bauer HC. Survival, complications and outcome in 282 patients operated for neurological deficit due to thoracic or lumbar spinal metastases. Eur Spine J 2006; 15: 196-202. 